\section{Annual weigh variation in mature cats}

\section{Nathalie Dowgray ${ }^{1}$, Kelly Eyre ${ }^{1}$, Gina Pinchbeck ${ }^{2}$, Eithne Comerford ${ }^{1}$, Vincent Biourge ${ }^{3}$, Alexander German ${ }^{1}$}

1 Institute of Ageing and Chronic Disease, Liverpool, United Kingdom

2 Institute of Infection and Global Health, Liverpool, United Kingdom

3 Royal Canin Research Centre, Aimargue, France

\section{OBJECTIVES}

To determine the magnitude and seasonality of variations in bodyweight measurements from client-owned cats enrolled in a wellness programme.

\section{METHODS}

Records were available from 31 mature cats ( $\geq 7$ years) attending the Royal Canin Healthy Ageing Clinic. Variation as a percentage of body weight at enrolment was calculated for each cat.

\section{RESULTS}

Weight change was minimal,

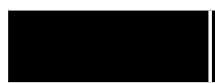

Six month

Twelve Month

\section{Median (\% change in BW) $-0.4 \%$ $-2.7 \%$ to $4.4 \%$ $-5.3 \%$ to $2.4 \%$}

Cats were then assigned to groups based upon the time of year they were enrolled (Q1 winter, 4; Q2 spring, 16; Q3 summer, 11).

\begin{tabular}{|c|c|c|}
\hline & $\begin{array}{l}\text { Six Month Median } \\
\text { (\% change in BW) }\end{array}$ & $\begin{array}{l}\text { Twelve Month Median } \\
(\% \text { change in BW) }\end{array}$ \\
\hline Winter & $\begin{array}{l}-1.45 \%(I Q R- \\
2.035--0.85 \%)\end{array}$ & $\begin{array}{l}-1.55 \%(I Q R-3.13- \\
-0.55)\end{array}$ \\
\hline Spring & $\begin{array}{l}0.18 \%(I Q R-3.0 \\
-4.85)\end{array}$ & $\begin{array}{l}1.5 \% \text { (IQR } 0.55 \text { - } \\
3.89)\end{array}$ \\
\hline Summer & $\begin{array}{l}-0.31 \%(I Q R-3.1 \\
-4.58)\end{array}$ & $\begin{array}{l}-4.8 \%(I Q R-7.58 \\
-1.625)\end{array}$ \\
\hline
\end{tabular}

There were no statistically significant differences found between these three groups at the 6 -month time point. However, at the 12-month time point, cats enrolled in Q2 were significantly more likely $(P=0.020)$ to have gained weight then cats that were enrolled in Q3

\section{STATEMENT (CONCLUSIONS)}

This preliminary work suggests a seasonal effect on the bodyweight of mature cats. However, these findings should be confirmed by assessing a larger group of cats over a longer period

\section{How old is your cat?}

\section{Kelly Eyre ${ }^{1}$, Nathalie Dowgray ${ }^{1}$, Gina Pinchbeck ${ }^{2}$, Vincent Biourge ${ }^{3}$, Alexander German ${ }^{1}$}

1 Institute of Ageing and Chronic Disease, Liverpool, United Kingdom

2 Institute of Infection and Global Health, Liverpool, United Kingdom

3 Royal Canin Research Centre, Aimargues, France

\section{OBJECTIVES}

To explore the accuracy of veterinary age assessment in mature cats and the effect that health status may have on the visual appearance of age.

\section{METHODS}

Data were collected from 135 mature cats (7-10 years) enrolled at the Feline Healthy Ageing Clinic at the University of Liverpool. At time of enrolment, owners completed a questionnaire which gathered information on date of birth, whether this was an estimate or was known, details of where the owner had acquired the cat, and how old the cat was when acquired. At their initial appointment, each cat had a thorough physical examination, and routine clinicopathological assessments (haematology, serum biochemistry and urinalysis). The attending veterinary staff (KJE, NJD) also subjectively assessed whether the cat: looked younger than their reported age', was 'age-appropriate', or was 'older than their reported age'. Cats were also subjectively classified as being 'healthy', 'in fair health' or 'in poor health' based upon physical examination findings, details in their electronic patient records, and results of routine clinicopathological tests. For comparison, cats were grouped according to the accuracy of their age, summarised below.

\section{RESULTS}

An accurate age was known for 73 cats (54\%), a close estimation was known for 22 cats $(16 \%)$, and age was not accurately known for 40 (30\%) cats.

Cats with an inaccurate age were 5.9 times more likely to have poor health $(95 \% \mathrm{Cl} 1.2-29.3)$. A cat that looked older than its purported age was 18.6 times more likely to have poor health $(95 \% \mathrm{Cl} 3.9-88.0)$. 


\begin{tabular}{|l|l|l|l|l|l|}
\hline & & \multicolumn{2}{|c|}{ Subjective age assessment and health status } \\
\hline & $\begin{array}{l}\text { Number } \\
\text { of cats }\end{array}$ & Younger & \multicolumn{2}{|c|}{ Age appropriate } & Older \\
\hline $\begin{array}{l}\text { Accurate age (DOB known or } \\
\text { acquired as a kitten <12w) }\end{array}$ & $73(54 \%)$ & 15 (0 in poor health) & 53 (0 in poor health) & 5 (1 in poor health) \\
$\begin{array}{l}\text { Close estimate (DOB not known but } \\
\text { acquired as a kitten <24 w) }\end{array}$ & $22(16 \%)$ & $3(0$ in poor health) & 17 (1 in poor health) & 2 (0 in poor health) \\
\hline $\begin{array}{l}\text { Inaccurate }>\mathbf{1 2} \text { years (exact age not } \\
\text { known, but acquired as adult) }\end{array}$ & $40(30 \%)$ & $4(0$ in poor health) & 27 (1 in poor health) & 9 (4 in poor health) \\
\hline
\end{tabular}

\section{STATEMENT (CONCLUSIONS)}

A significant proportion of middle-aged cat have a potentially inaccurate age. The observation that cats who appear older than their purported age are at higher risk of being in poor health is clinically applicable. Such observation could be used to prompt veterinarians to perform further diagnostic investigations.

\section{Deslorelin implant as a treatment for temporary infertility in tomcats}

\author{
Kaisa Savolainen ${ }^{1}$, Merja Dahlbom ${ }^{2}$ \\ 1 Estonian University of Life Sciences, Tartu, Estonia \\ 2 University of Helsinki, Helsinki, Finland
}

\section{OBJECTIVES}

Biggest reasons for temporary infertility treatment in tomcats are undoubtedly unwanted urine marking, vocalization, behavioural changes and poor appetite. Deslorelin is synthetic gonadotropin-releasing hormone agonist used to induce temporary infertility. At the moment use in cats is off-label and there is only little research done on the subject.

\section{METHODS}

Study was done as online survey to cat owners who have used the implant on their tomcats.

\section{RESULTS}

In total 486 answers were given from 28 countries and 31 different breeds. $70.8 \%$ of cats had offspring before implant and $89.2 \%$ of the cats got offspring after implant. Average age at implantation was $24.1 \pm 14.6$ months. In average the effect lasted $14.8 \pm 6.0$ months. It significantly reduced $(p<0.0001)$ urine marking, vocalization, aggressiveness, restlessness and weight loss. Smell of pee decreased in $87 \%$ and testicle size decreased in $91 \%$ of the cats. Weight gain was reported in $77.5 \%$ of the cats. The implant had no effect in $2.1 \%$ of the cats. $19.5 \%$ tried to mate females in heat even without any other signs of stud behaviour and $5.3 \%$ got offspring during the implant. In $17 \%$ of cats the effect of second implant lasted longer than first and in $27.4 \%$ the effect ended earlier. $93 \%$ of owners had positive overall experience of the implant.

\section{STATEMENT (CONCLUSIONS)}

In conclusion, deslorelin implant is easy to use and can be used as a temporary infertility treatment in tomcats, but it is not $100 \%$ effective and tomcats with the implant should be kept separated from females they are not allowed to mate. 